\title{
Disruption to Embodiment in Autism, and Its Repair
}

\section{ACCEPTED AUTHOR MANUSCRIPT}

To be published in N. Papaneophytou \& U. Das (Eds.), Emerging Programs for Autism Spectrum Disorder. Academic Press.

The full copy-edited manuscript will be available at:

https://www.elsevier.com/books/emerging-programs-for-autism-spectrum-

disorder/papaneophytou/978-0-323-85031-5

Please cite as:

Delafield-Butt, J., Dunbar, P., \& Trevarthen, C. (2021). Disruption to Embodiment in Autism, and Its Repair. In N. Papaneophytou \& U. Das (Eds.), Emerging Programs for Autism Spectrum Disorder. Academic Press.

Jonathan Delafield-Butt

Professor of Child Neurodevelopment and Autism

Director, Laboratory for Innovation in Autism,

University of Strathclyde, Glasgow, Scotland.

E-mail: jonathan.delafield-butt@strath.ac.uk

Penelope Dunbar

Independent Artist and Creative Researcher, Glasgow.

Colwyn Trevarthen

Professor (Emeritus) of Child Psychology and Psychobiology,

School of Philosophy, Psychology and Language Sciences,

The University of Edinburgh, Edinburgh, Scotland.

E-mail: c.trevarthen@ed.ac.uk 


\title{
Disruption to Embodiment in Autism, and Its Repair
}

\begin{abstract}
This paper offers a neuroscientific explanation of life with autism which recognises that human behaviour and experience is by nature both personal and interpersonal. With a focus on insights of Penelope Dunbar (Pum) who has lived with autism for decades, we explore an affective neuroscience understanding of autistic experience and how to work creatively with its impulses for health and personal development. Pum describes her autistic disruptions to the intra-personal coherence of her basic states of being, moving-with-feeling in selfawareness, and how this disturbance to her internal subjective coherence of mind challenges her capacity to self-regulate arousal, and communicate with others. By examination of the source of her problems in childhood and ways of working with them, Pum has clarified fundamental elements in the development of her capacity to regulate self-care in creative efforts that facilitate both affective embodiment and sensory-motor coherence in growth of understanding in her mind and body. With her advice we explore how current neurobiological insights in autism as a disruption to the regulation of affective embodiment and sensory-motor integration leads to new recommendations for therapeutic care to relieve autistic distress and restricted modes of being. Although particular to her circumstances and cultivated habits of autistic expression, this analysis offers insight into the fundamental nature of autism, and ways of positive working with one's autistic nature for creative gains.
\end{abstract}

Keywords: autism, affective neuroscience, embodiment, self-regulation, art, movement 


\section{Introduction}

In the human mind, consciousness of 'the self as agent' (Macmurray, 1957) is not a singular, homogenous phenomenon, but is a layered set of systems integrated by a hierarchy of phylogenetic principles of brain growth and animated activity that give rise to sympathetic actions and reactions that connect 'persons in relation' (Macmurray, 1961). Comparative neuroscientist of emotions, Jaak Panksepp (Panksepp, 1998a; Panksepp \& Biven, 2012). identified three levels of neural processing in mammals, each generating an awareness of the Self made in relation to internal and external environments, and mediating between the two. His view advanced by detailed comparative neuroanatomy with penetrating observation of affective expressions and responses common to rodents and primates gave psychology improved description and richer evolutionary understanding of the basic notion of a 'triune' brain of Paul MacLean (1990) - the idea that evolution of vertebrate ecology in social groups toward the human cultural intelligence incorporated three distinct, but inter-connected levels of processing. First of the reptilian brain stem, then the palaeo-mammalian midbrain limbic system, and finally the complex neo-mammalian powers for acquiring adaptive experience recorded in what is known as the neocortex of the forebrain.

What a human person experiences in healthy activity of the body and brain with awareness as a singular coherent conscious Self (Sherrington, 1906) is the result of efficient composition of action in the layers of neurobiological processing working in synchrony (Buzsáki, 2006). Regulations of energy in internal embodied well-being of an integrated person is maintained by an affective system linked to the autonomic visceral organs (Panksepp, 1991; Panksepp, 1992), and this is coupled with all voluntary and imaginative neuromotor control of the skeleto-muscular system of the body in purposeful movement (Bernstein, 1967). This 'inner life' from which all arts, mathematics and philosophies grow (Langer, 1942; Lashley, 1951) is both graceful or aesthetic in its efficiency (Turner, 1991), and gracious or moral in intersubjective social cooperation (Trevarthen, 2015).

Efficient communication between all the elements of the intentional and self-conscious nervous system in one rhythm of time (Buzsaki, 2006) is critical. The animal brain evolved as an integrative organ to bring the experiences and activities of all parts of the body into one composite awareness. In human beings the fingers, hands, elbows and feet move the body in ambient and focal awareness to exploit what the outside world affords for use (Gibson, 1977). Inner vitality coordinates functions of the stomach, liver and heart, and the informationseeking assertions of neck, head, mouth and eyes that become powerful media of communication of individual impulses and their effects in social partnerships (Reed, 1006). Every movement acts as a coherent and coordinated whole with its own, singular purpose in transformations of the body made in movement with prospective imagination of the effects (Bernstein, 1967). The innate coherent rhythmic 'musical' composition of all wilful agency of the individual is elaborated within each body as the common code for shared cultural awareness and understanding (Malloch \& Trevarthen, 2009b; Trevarthen, Gratier, \& Osborne, 2014).

At the anatomical centre of this integrative system of neurons in all vertebrates is the brainstem. At the anterior end of the spinal column it brings together information from the visceral organs on maintenance of inner life, and information from the moving muscles of the skeleton together which sense information about the surrounding world from the distance 
receptors, the eyes, ears, and nose for sight, sound, and smell. This brainstem 'head ganglion' (Coghill, 1929), has access to all of the information from outside and inside the body required for prospective conscious awareness along the intended course of locomotion. It's basic anatomy and neural function is shared across 'vertebrates' - all animals with a spine; reptiles, amphibians, birds and mammals. As the most ancient phylogenetic layer of this neural system it is the site of rapid integration and evaluation of information across the body and brain, in what Panksepp calls the 'Core Self', the first 'centre of conscious awareness' (Northoff \& Panksepp, 2008; Panksepp, 1998b).

Interestingly, and importantly, this Core Self can operate on its own in humans, cats, and rats, without the addition of information from the phylogenetically more recent neocortex - the large, voluminous convoluted brain mass that fills the skull and that most educated people (including cognitive neuroscientists) think of as 'the brain' (Bjorn Merker, 2007; Penfield \& Jasper, 1954). In fact, we can be conscious without a cortex, as surgical decortication experiments have shown, and as is proven by children born with rare congenital total loss of neocortex (Shewmon, Holmse, \& Byrne, 1999). This simple fact is lost in most contemporary neuropsychology sources, but it is critical to our understanding of autism. The brainstem is the site of coherent integration of information about the world outside in consciousness, and also of the state of the world inside, rich with vital needs of the body, which are afforded opportunity for satisfaction in active appreciation of benefits, and apprehension of dangers, in contacts with the world outside.

Second, above the brainstem sits a complex of pathways and larger nuclei that hold special abilities to store memories and appraise these as benefits or risks of harm. These store and organise past experience so it can be recalled and deployed to help organise action in the present moment, and in service of future goals. The accumulated memories of the past serve understanding of the consequences of actions in the present, and set goals for a desired and imagined future of purposeful life.

In the third level of organisation experiences grow with our expanded cognitive or 'knowing' capacities, and with tools of symbolic abstraction that enable defined experiences to be held 'off-line' in memories and manipulated in our imagination. This third level of processing occurs across the vast array of brain space we recognise as the cortex. It's unique format presents layers of neurons stacked as vast, broad sheets of integration that can process the rich variety of experiences near-simultaneously. This new element of the brain provides capacities of enhanced perceptual discrimination, memory, abstract reflection, conceptual organisation, planning, and evaluation. These 'cognitive tools' become the structures that build our human intelligence, knowledge, and technical mastery (Gigliotta, Pezzulo, \& Nolfi, 2011; Pezzulo \& Castelfranchi, 2009). It is the seat of our post-industrial rational human mind and reflective pragmatic intelligence recorded symbolically in manufactured media.

Our conscious experience in each moment varies and shifts, contingent on changing needs and circumstances. It is a single point in what William James called 'the specious present' (James, 1890), a unique moment in time that slips ever forward, its experience structured by the remembered past and anticipated future. We now understand its structure is the product of deep evolutionary layering, adapted for an adventurous animal life that expands our ability to anticipate and prepare for the organic needs of growth, sustenance and learning especially highly developed in humans. It enables an exceptional capacity to project the imagination into the future, to make plans in the present moment based on a remembered past, for a desired future (J.T. Delafield-Butt \& Gangopadhyay, 2013) (Figure 1). 
Jaak Panksepp's three levels of conscious processing demonstrate that what we have traditionally considered 'unconscious' is in fact the core of our conscious experience - it is a primary, pre-reflective consciousness that is evident in, and that structures, everyday actions of the animal. As Solms and Panksepp (2012) put it in their title, "The "Id" knows more than the "Ego" admits." We accept this as the hierarchy of human motor intelligence, and how it grows between the intuitive invention of activity in awareness of the body, and the articulate record and interpretation of thinking with semantic codification of foci of interest in gestural and linguistic syntax with affective prosody (Delafield-Butt \& Gangopadhyay, 2013; DelafieldButt \& Trevarthen, 2015; Malloch \& Trevarthen, 2009a; Trevarthen \& Delafield-Butt, 2017).

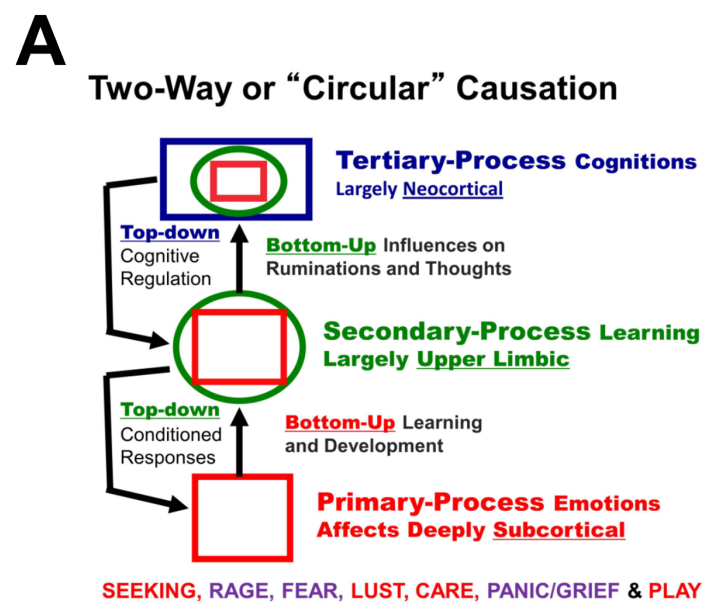

Nested BrainMind Hierarchies

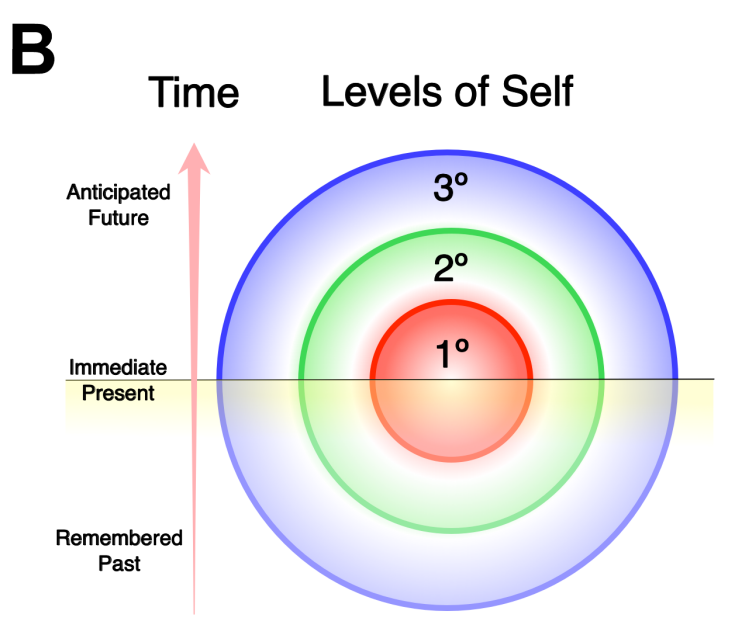

Integrated Experience of Nested BrainMind Hierarchies

Figure 1. Schematics of the nested layers of the Self showing $(A)$ their nested organisation (reproduced from Solms and Panksepp, 2012) and (B) their integration and contribution to experience over time. The primary, core self is the most phylogenetically ancient and therefore ontogenetically primary self - a site of integration of integrative, evaluative experience and agency. This is brainstem mediated. The secondary self stores with greater precision the memories with greater powers of discrimination for evaluation, but finally the tertiary self is empowered with the cognitive tools built on abstraction from primary experience through its secondary process and considered 'offline'. Cortically mediated. These layers of processing are reflected in the artwork, "Profile of a collaged mind, finding sense through fragment and movement - autism as sensory motor disruption to core self", shown in Figure $2 b$.

\section{Autistic Experience as a Disruption of the Primary Affective Self, and its Coherent Integration with Secondary and Tertiary Processing}

In this paper we examine lived autistic experience to reveal its nature in light of the vertical organisation of mental processing. We build on self-reflection, scholarship, and dialogue between Penelope Dunbar (Pum) and Jonathan Delafield-Butt, made in recorded interviews about Pum's life with autism over a period of five years, and placed into context of a 
developing understanding of autism from an embodied, ecological perspective developed earlier between Jonathan Delafield-Butt and Colwyn Trevarthen (Delafield-Butt \& Trevarthen, 2017; Trevarthen \& Delafield-Butt, 2013a). We have worked to understand the structure of her experience as a person diagnosed with autism spectrum disorder from a phenomenological, lived perspective and have set this within new theoretical understanding of autism as a disorder or distortion of a particular kind of embodiment of human agency, distinguishing the regulation of purposes by levels of feeling in body movement, affective appraisals and arousal, and their communication (Trevarthen, 2014). Therefore, the experiences and conclusions drawn from these are relevant for this one particular autistic individual, and we can guarantee their accuracy as reported.

However, autism is not a simple variation of normal motivation and intelligence. It is recognized as a very varied state of personality and in each case manifests its spectrum of conditions idiosyncratically (Hobson, 1993; Gillberg, 1992; Hobson \& Hobson, 2011). ${ }^{1}$ Therefore, although not all of our findings from Pum's account will generalise or fit as one correct description of the condition, we do emphasise the manifestations in it of general truths applicable to all human beings concerning feeling, arousal, the nested organisation of conscious experience, and the effects of these manifest in the embodiment and learning of intentional action. The basic facts of motivation for human life are common to individuals with their different characters and experiences, and a typical disruption of these within autism may be identified.

\section{A Brainstem Sensorimotor Disruption in Autism}

Our account of autism emphasises a disruption to efficient primary processing of sensorymotor information, and the self-related affective processing that mediates arousal regulation and coherence of motivation within Panksepp's Core Self (Figure 1; Delafield-Butt \& Trevarthen, 2017; Delafield-Butt, Trevarthen, Rowe, \& Gillberg, 2019; Trevarthen \& DelafieldButt, 2013a). In this paper, we extend this account of a disturbance of self-regulating vitality to include a specific disruption in the coherence of consciousness vertically, between its three levels of processing. This weakening of coherence appears to start within the primary, brainstem processing that integrates the Core Self, affecting first its internal coherence, and subsequently its elaboration through participation in processes of the higher levels. In this regard, it is from a weak central coherence of primary consciousness, not one limited to particular higher-order cognitive and perceptual domains of the traditional theory that emphasises focal perceptual attention to integration of parts (Happé, 1999, 2003; Happé \& Frith, 2006; Happé, 1997; Happé \& Booth, 2008), rather than a whole single system rich with affectivity and the spirit of vitality and awareness. We draw out aspects of conscious experience below tertiary cognitive processing that the weak central coherence theory (Happé \& Frith, 2006) attends to, to show a more fundamental global 'weakening' of conscious coherence that involves affects, arousal, and the centre of gravity of one's conscious awareness.

Our account recognises and appreciates the fundamental contribution to conscious thought, feelings, and awareness the brainstem complex provides, not only in terms of organising information, but in terms of organising one's subjective awareness. And although the

\footnotetext{
${ }^{1}$ As the autistic community points out, "if you've met one person with autism, you've met one person with autism".
} 
brainstem may be anatomical subcortical, its function is ontogenetically supra-cortical, giving patterns and structure to cortical development and processing in organization of bodily activity (Merker, 2005, 2013), and the generation of subcortical rhythms that patterns cortical cohesion (Buzsáki, 2006).

An intra-personal coherence between levels of processing appears disrupted, which prevents the development of the innate function of the core self in regulating affective states, and that disrupts efficient agency and inter-personal communication recognised in formal clinical autistic symptomology.

\section{Autistic Challenges of a Disconnected and Incoherent Core Self}

In Pum's experience, she felt a distressing disjunction between her rational, reflective self and her inability to manage her affective states of arousal. Her core affective and integrative corporal self was disconnected and muted. Her reflective tertiary self became obsessively aware of her social expectations, and its demands for her to perform in a socially conformed manner. This logic produced a 'false' rationale because it excluded personal feeling and motive, but it dominated her thinking and reflection and came to control her conscious experience and behaviour. It was an inflexible, literal appropriation that accepted what she was taught and led to a rational rule-governed understanding of social requirements and engagement in them. Yet, this rational self-control of her behaviour neglected her more fundamental needs for self-knowledge and self-satisfaction as an individual animal with impulses and feelings, which were denied to her. Instead, compliance to learnt social scripts were supported at the cost of her emotional wellbeing. Later, her ability to regulate states of arousal and anxiety were paralysed by a disconnection and in many respects were completely unaware of what we have come to identify as the feelings and needs of her Core Self. Further, this habitual disassociation into a performed script damaged her ability to manage her basic functioning, and manifested in, for example, eating and sleeping disorders and entrenched mental health problems in her early adult life.

The language of the core self is non-verbal, affective and aneotic (Vandekerckhove \& Panksepp, 2009). In childhood learning Pum was instructed how to understand and use social verbal language. And she worked hard to learn speech, reading and writing through copying particular demonstrations of these, and with obsessive attention to detail of politeness and needs of others. This led to an unintegrated sense of self, which was eventually expressed in mental health symptoms of chronic anorexia and depression. It was only many years later in adult life, after ongoing therapy and some decades of self-reflection and analysis that she came to understand that she had developed a disjunction between what we now know as her Core Self - her core affective, perceptual, and embodied Self - and her more artificial, rational, and reflective Tertiary Self. The logical language of words were not expressive of her true intuitive self-as-agent with its idiosyncratic autism profile, accepting it, and therefore did not communicate what she really wished to do and share.

\section{Meaning, Coherence, and the Challenge of Incoherence}

We are a social species that demands meaningful social interaction, even in autism (Jaswal \& Akhtar, 2018). Social isolation is a painful experience and can be associated with feelings of shame on both sides (Trevarthen, 2005), it disconnects the inter-personal world from a 
system evolved to share in it (Gallagher, 2014). Similarly, disconnection within oneself can be painful. In Pum's autism, centres of conscious experience evolved to work integratively as a whole were disconnected from each other, and intra-personal disconnection. Failure of a coherent, integrated experience of behaviours and interactions left each less meaningful, and created distress and challenging behaviours as a consequence. Left unattended to in childhood, this lack of depth of meaning created despair and anxiety that became the standard in her adolescence and early adulthood.

On the surface, she had adjusted her social relationships to appear acceptably 'normal', but she struggled in private with an array of distressing and challenging behaviours hidden from view. Internal incoherence and neglect of more primitive, subsurface feelings and desires led to significant mental health issues, especially apparent at peak life events, such as the transitions of puberty and to adulthood, and in the event of life's challenges affecting love, loss, desire, and change of 'home'. Her Core Self that worked to integrate somatic physiology, including satiation in feeding, digesting, sexual awareness, affectionate engagement, and satisfaction, and sleep/wake regulation, was disengaged from her public behaviour.

In childhood, Pum learned language rationally, 'outside' of her body. She became more and more disconnected from the life of the body and its needs for self-regulation as the years went by. And, by copying sounds, which then became learnt codes for behaviour that were socially appropriate, she could present herself as appropriate, but these were personally meaningless to her.

Johnson and Lakoff teach us how 'being in the body' grows into language (Lakoff \& Johnson, $1980,1999)$, a feature missed or reduced in Pum's development. In typical ontogenesis, one develops movement first, and feelings expressed in movement generate the inspiration for expressive language (Delafield-Butt \& Trevarthen, 2013; Delafield-Butt \& Trevarthen, 2015; Iverson, 2010). It is only once this affective experience of being has found its primary, intuitive, and embodied language can it be developed into an expression of reaching out and sharing what is internal with those who are physically external. Only once this is achieved can the meaningful shared communicative verbal language of words be placed on top, and the possibility of authentic communication established.

Lessons in language development offer a particularly useful illustration of how a supportive parent, therapist, or teacher can encourage healthy curiosity and enjoyment of animated learning. The expressive language of the emotions and body come first in development, on which the language of words bears depth of meaning, and purpose. "It is by natural signs chiefly that we give force and energy to language; and the less language has of them, it is the less expressive and persuasive." (Reid, 1764) (pp. 106-107).

\section{Implications for Self-Improvement and Therapeutic Support of Autistic Disturbance to the Core Self}

If our account of the disruption to the coherence of core experience of self and its communication with higher level processing is correct, then focussing therapeutic intervention on overt behaviours and conventional speech production may miss the mark, 
over-shooting a coherent integration of feelings and impulses of the affective Core Self. Ontogenetically one must work to develop and substantiate the primary levels of processing first, before extending to more advanced forms such as social regulation, speech production and verbal communication. One must first build an intimate an affective 'languaging' of the self (Halliday, 1975, 1978).

The core self is principally embodied, enactive, and non-verbal, so stories of language-like understanding can be first formed on a non-verbal sensory and motor level, as artful visual imagery or musical auditory patterns (Malloch, 1999; Malloch \& Trevarthen, 2009a, b), and within the level of the physiological regulation of the communicator's body and its inner life, as in 'polyvagal theory' of the emotional nervous system and expressive forms of movement for communication (Porges, 2001). For therapy, deploying creativity and playful movement in an asocial, structured environment paying particular attention to detail and consistency of the routine to support the patient's growth within the condition of autism, rather than setting a priority on teaching technical performance and social rules where one may unwittingly be led to prioritise performance rather than intuitive knowing what is intended and felt, may be more effective in engaging, or facilitating, the whole, integrated self of the individual with autism.

We have found strong physical activity can also be therapeutic, such as in sports, dance or equine therapy (Ford, 2013; Koch, 2016; Koch et al., 2015; May et al., 2019; Rinehart, Jeste, \& Wilson, 2018), or in shared movement-regulating programmes, such as that based on the agency-guiding education theory of Geoffrey Waldon (Solomon, Holland, \& Middleton, 2012; Posner, 2016). In the activity of 'doing', the sensory and motor system embeds, supports and physically yolks experience to the active sensory-affective self. Further, creative process and movements can become tools when they are built into established daily and weekly structured routines that are organised and predictable.

We caution that the individual with autism needs special support to access and maintain these routines adequately. A low arousal, structured and predictable lifestyle can support overall wellbeing and regulation. Without support for routines, feelings and self-agency may be inaccessible, blocked by executive function difficulties in planning, preparation, and organisation.

First, for growth and learning, one must be confidently centred within oneself. The human organism must come to terms with the innate complexity of its own movements, expressions, and desires, and able to experience these as self-expression of ' $\mathrm{Me}^{\prime}$ ', before one can differentiate him or herself from the actions of another.

"In the course of emotional development of the individual a stage is reached at which the individual can be said to have become a unit.... At this stage the child can say 'here I am'. What is inside me is me and what is outside me is not me. The words inside and outside here refer simultaneously to the psyche and to the soma... A satisfactory psychosomatic partnership." (Winnicott, 1971/2001, pp 130-131)

The centre is first and foremost our embodied Core Self, the brainstem-mediated ontogenetically primary agent who perceives, feels, anoetically evaluates without conscious definition, acting without the 'superior' reflective consciousness mediated by our cortical cognitive systems (Vandekerckhove \& Panksepp, 2011). One must first 'get into the body' with the felt life of wilful movements (Lakoff \& Johnson, 1980, 1999). 


\section{Getting into a Routine}

However, we must appreciate that activities of integrated movement may not be physically or psychologically available or accessible to a person with ASD. There is an anxiety specific to autism provoked by the beginning of any new act (Robledo, Donnellan, and Strandt-Conroy, 2012), and it takes time for the individual to feel safe and allow arousal levels to settle. Accessing movement for personal or social aims can over-excite uncertainty, "Am I going to be able to move my body?" This can be debilitating, and prevent wilful transition into the activity. However, with external support for practice of a daily and weekly routine, the impulse to act can recover with feelings of safety, and the body can begin to associate the beginning of that structured routine with a sense of confidence in knowledge of the future activity.

How Emotional Arousal can be Understood, and Managed.

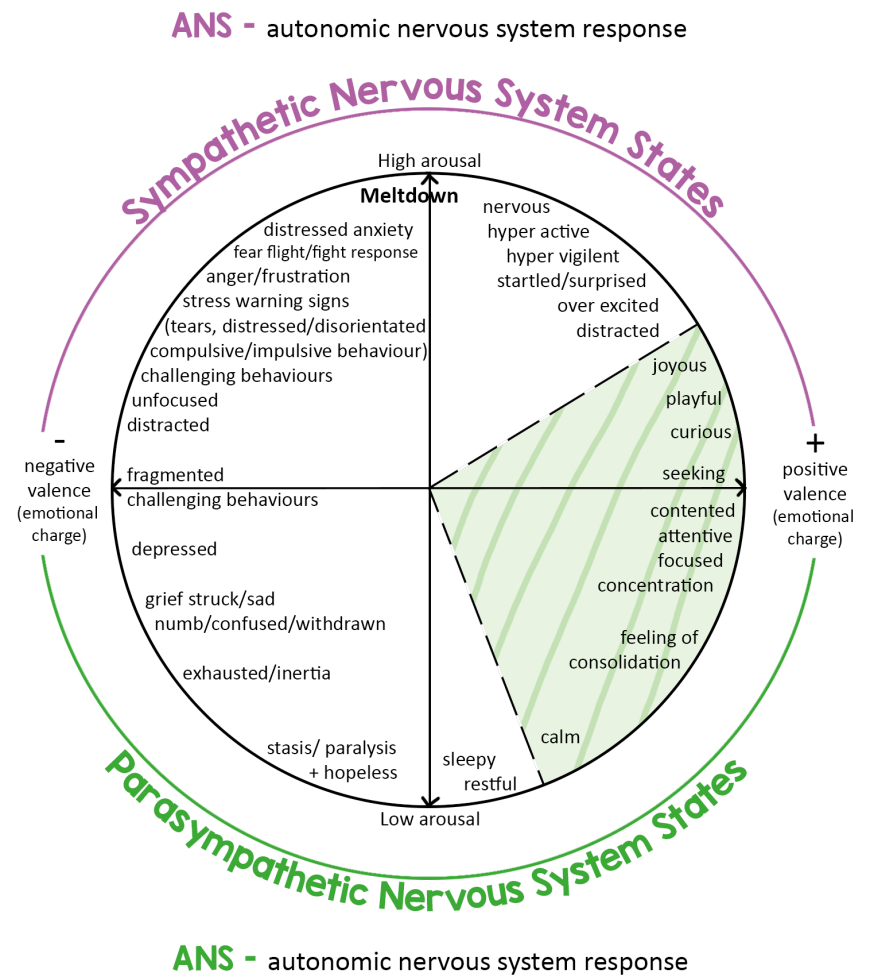

Figure 2. Pum's states of subjective, internal regulation of affects and arousal by body activity, their personal expression and interpersonal sharing in movement. The green area indicates the optimum, ideal levels of arousal for practicing structured and creative routines in kinetic expression, and to facilitate 'self-to-self' communication across levels (c.f. Fig. 1). The left-hand side of the chart shows negative balance states, feelings that are detrimental to individual functioning and wellbeing and that incur further stress. The right-hand side of the chart shows more positively valanced feelings. The higher regions of arousal on this side 
can still result in an unpleasant and detrimental response. States of happiness and surprise are especially triggering, and stressfully disorientating. Being over-excited makes Pum dissociate and become over-stimulated, which often results in an inevitable shift to meltdowns and anxiety, leading to disorientation, confusion and a grief-stricken state.

When a child's or an adult's autism's needs are not met, their levels of arousal increase, and they may appreciate even a sensitive invitation as disorientating. The individual requires an adapted calm responsive treatment, which offers containment and a neutrality that accepts and attempts to moderate their reactions of distress (Douglas, 2007).

At first, the companion, supporter or therapist may work alongside the individual. This may help to foster oblique communication by removing face-to-face interaction which can be experienced as overwhelming and confrontational for the individual with autism. Imitating and helping to organise the routine of their actions, acting as a coach or guide to help regulation of their movement and to confirm a sense of coherent agency. A therapist who is patient, committed, and observant of patterns of action may act with aesthetic and compassionate feelings that recognise the unique autistic needs of the individual in the present moment.

The practitioner's actions need to be predictable and consistent for the person with autism to feel accepted, safe and their needs appreciated. Then they can begin to become aware of what those needs are, safe in the knowledge that the other is able to foster trust and lower arousal. From this foundation in mutual regulation of self-awareness and trust, the more creative organic platform of communication for the self through structured, repetitive activity can be developed. This way autonomy can be promoted, and eventually secured. Communication from within the Primary Self leads to a growing potential to meaningfully communicate with another person as a more authentic, confident, and true Self.

\section{Co-opting Compulsions for Repetitive Behaviours, and Transforming Them into Productive, Creative, Self-sustaining Action for Personal Growth}

Self-expression is built and shared in efforts of sport and art, but their aesthetic and moral power in shared vitality can be devalued and often overlooked in Psychology, even as music has been by Stephen Pinker, follower of Noam Chomsky's theory of the rational formality of language (Chomsky, 1957), on 'the language instinct' (Pinker, 1994).

With the information obtained by detailed analysis of the talents of infants for sharing stories of life in movement (Trevarthen, 2003; Trevarthen \& Delafield-Butt, 2013b; Trevarthen \& Delafield-Butt, 2015), we see these activities and the routines that lead into them as fundamentally important for personal well-being, growth, and mental health of every human being. From before birth, as a foetus alive and responding to feelings with the mother's person, each individual adapts the vital compulsion for rhythms of repetitive action (D. N. Stern, 2000; Daniel N. Stern, 2010), and co-opts this to serve useful purpose in special ways of living in the objective and social worlds. Their co-option affords gains in self-control, selfsatisfaction, and learning with a shift in mental processing that is felt, from the start, as a 
cohesive and integrative embodied experience, a story of human life to be shared (Bruner, 2003).

In infants with autism, their co-option into habits of shared social value is disrupted (St Claire, Danon-Boileau \& Trevarthen, 2007; Trevarthen \& Daniel, 2005). Repetitive movement without a plan or narrative that gives a clear beginning, middle, and end to the project (Trevarthen, Aitken, Nagy, Delafield-Butt, \& Vandekerckhove, 2006) can produce compulsive repetition of behaviours. Some stereotypies of gesture, such as hand flapping, can be selfconfirming, allowing one to hold a presence of mind for useful benefit in self-regulation (Caldwell, 1999, pp. 16). Others can be detrimental, such as excessive consumption of water or food, or teeth grinding. When over-done, their beneficial effect is lost to a detrimental, sometimes damaging form of loss of control, such as in compulsive eating, biting, or extensive habits that cause damage to the body. In Pum's experience, the self-affirming quality of repetitive action contains within it a valuable resource to be harnessed.

With care to bring into life a structured routine that has a clear narrative purpose, with a meaningful beginning, middle, and end, security in predictable rhythms of action can be recovered. However, without this structure and routine the autistic individual may lose that coherence of purpose, not know what one is doing or what to do, and it can be very difficult to step over into the activity or the movement, particularly the transition from a mental, imagined into physical, active state. This particular emotional autistic sensitivity needs to be supported. Movement and the creative process within a regular routine can support the individual.

Pum has shown that the power of two routines she has developed over many years can coopt her autistic needs for repetition and regularity, but also her needs for body movement to feel alive in the body and in her mind. These two activities are swimming and collage, different in the degree of physical exertion, but similar in their adoption of repetition and routine for beneficial gains, and a unique and particular transformation of state of mind that is of special interest to our developing thesis on the Primary Self.

Pum's swimming routine was developed over ten years of practice and serves as a selfgenerated intervention to manage her autism and its associated depressive mood disorder. Exercise benefits regulation of appetite, sleep, hygiene, and also creative imagination. Second, she has always deployed art for cathartic expression, particularly painting. From her creative, artistic research grew collage praxis. Collage satisfied a need for an expansive, yet concrete visual language. It further helped her to explore her autism, her sensory sensitivities, disruption to her embodied being, and difficulties managing her lived experiences.

We explore the details of each, in turn. Each is predicated on sensorimotor repetition, sensory-motor loops (cf. Daniel, 2019; Trevarthen, Daniel, \& Trevarthen, 2017). Each practice is a routine that involves ritualised regularity of the tasks before, during, and after it, for example in the days of the week, time of day, and pattern of preparation, practice, and conclusion. Each is itself a regular, repetitive routine, but it's sensory-motor nature does something peculiar for Pum's state of mind, improving her clarity, reducing her autistic anxiety, and enabling a cohesion in her sense of Self that bridges between her rational tertiary self and her core self. Both give integration through movement. 

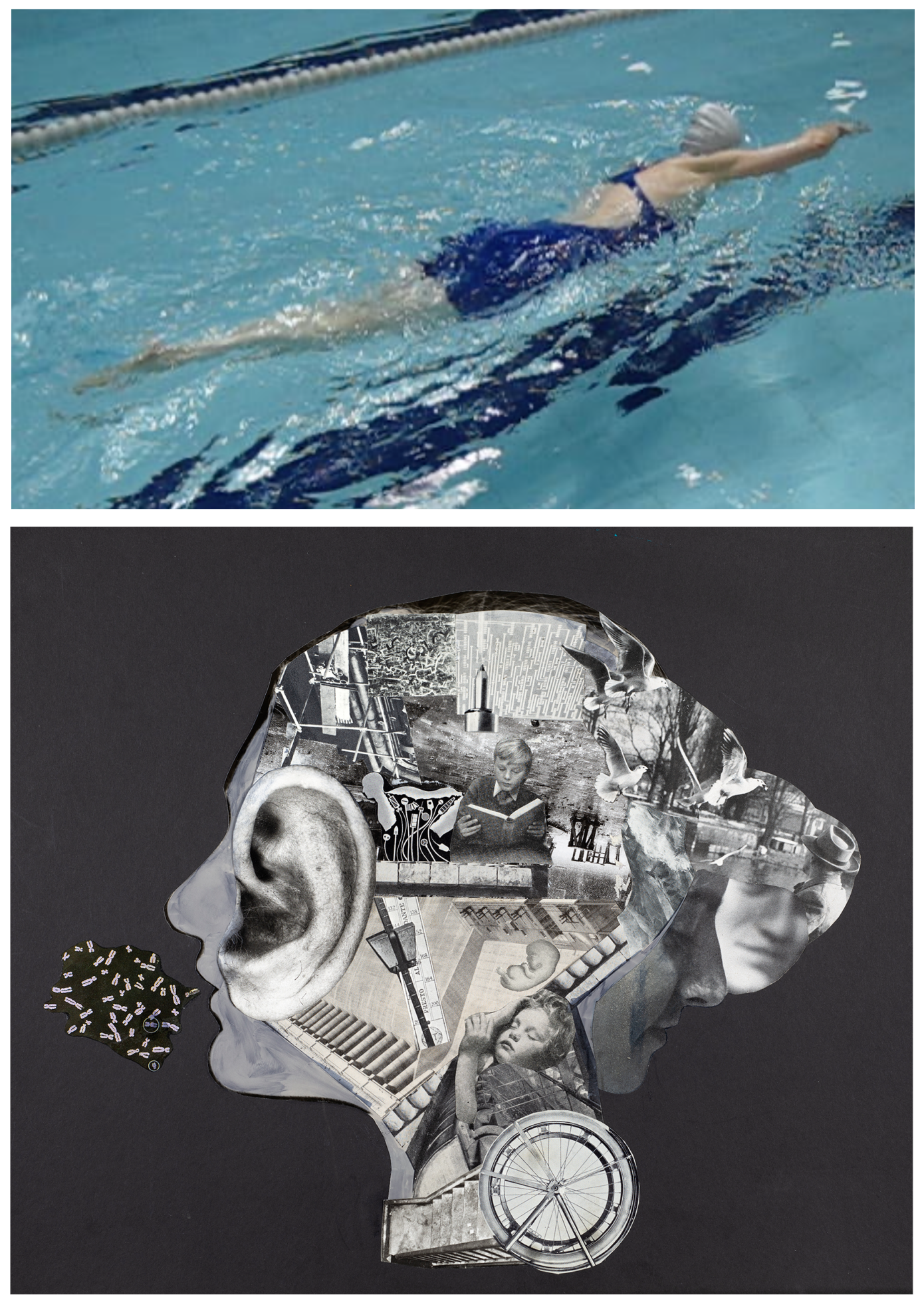

Figure 2. Above: Pum enjoying moving her body through the supportive medium of water which offers routines of sensorimotor integration and progress in movement. Below: An original collage artwork by Pum that explores and expresses visually a growing understanding of the neurobiological basis of autism spectrum disorder. The foetus represents the core self, and the collage spatially positions images in correspondence to the brain locations of various structures to represent those functions. See Appendix 1 for a full key to the component parts. 


\section{Swimming as Creative Therapy}

The cycles of body movement in swimming are repetitive and predictable over a series of time-scales. They are carried out in a specially constructed swimming pool environment which stays constant, improving the regularity of the experience. Each length of the pool is the same as the next or the last, and each lap repeats a loop of the same action architecture. Thus, the repetitive nesting of voluntary neuromotor actions creates and sustains a regularity of acting, one that is generated and controlled by the individual's own wish, and will, to swim.

Swimming creates a sensation of a moving and floating Self made by making sinuous movements of the whole body pushing against the water by cyclic strokes of legs and arms, coordinated to follow a particular course with more or less vigour. It requires exercise of repetitive sensorimotor loops guided by bilateral actions with unique kinetic and proprioceptive properties. The body is suspended with a feeling of weightlessness and sufficient buoyancy to hold it at the surface in any posture, but able to dive by pushing downwards. With any movement the water provides a tactile feedback over the body's surfaces, and muscular-skeletal feedback is felt internally by proprioceptive stimulation from actions slowed by the resistive forces of the water.

Regular, repetitive sensory-motor loops of arm, leg, head, and body posture in synchrony are paced and forced with direction in space and time to produce fluid movement of the whole body through the water. Separate actions are serially organised and coordinated to work in step with their kinetics slowed by the fluid mass in which they float. A front-crawl cycle of arm moves to push the body forward is made with adjustments of posture and head to afford breathing in time with the successive strokes of left and right arms in alternation, and the two legs kick in contrapuntal, anti-phase synchrony. Thus, simple actions of the limbs are serially organised and coordinated in time with breathing. Each cycle of limb actions conforms with the cycle of a whole-body pattern marked by breathing, which resets the cycle. A fixed project of these repeated actions moves the body to the other end of the pool where a different set of coordinated movements turns the person around to face the opposite direction, and the exercise repeats.

Using buoyancy of the body held with the liquid mass of water, swimming is regulated by kinetic proprioception of the body surface by a unique tactile feedback of counter-balancing muscular forces sensed simultaneously. With strong patterns of simultaneous feedback from trunk and all four limbs it can be particularly somatically integrative. It sets swimming aside as a unique exercise of all-body monitoring by sensory feedback. This appreciation of intentional action, coupling all modalities of sensory feedback, may have especially positive benefits for individuals with autism, helping them sense in fully-coherent self-control. It generates a physiological and psychological experience of unification: "I am, I be-come, I act embodied. My body is felt as mine." This relates back to Winnicott's understanding that, from the beginning of individual life, knowing your body as yours is primary, and essential for learning an understanding that your body is separate and distinct from any other person's body. Swimming builds up individual and relational awareness and creates a safe exploration in rhythms of movement for the experience of Self, to appreciate it is intact and truly inhabited with an ambitious will to live.

What Are the Special Beneficial Effects of Swimming for a Person with Autism? 
As with all repetitive, patterned activity, the exercise of swimming frees the conscious mind to reanimate a deeper, more primary physical awareness. The conscious attention required to perform a skilled routine is significantly reduced, which allows the sensuous part of the mind to become affectively engaged with the body, finding somatic satisfaction in the expression of movement. This can be felt as cathartic.

Generated and integrated within the brainstem at the level of Panksepp's 'Core Self', the underlying sensory-motor activity generates a rhythmic regularity and integration of experience at this primary level of integrative processing. The contrapuntal, bilateral repetitive movements together with haptic sensation of the whole-body to resistive forces of liquid flowing across it confirm a strong sensory-motor integration in active experience of beneficial for peaceful and pleasurable integration of mind.

Signals from rhythmic brainstem sensory-motor integration, in concert with the rhythms of action generation and sensory responses, are repeated through all their nested cycles in synchrony. The foundational rhythms of body movements, generated and integrated in the brainstem, pattern and structure the more speculative rhythms of neural activity in the cerebral cortices (Buzsáki, 2006). There, our abstract, 'off-line' intuitive, anoetic processes and reflections are aroused and coordinated by patterning of inter-neuronal activity excited from below (Pezzulo \& Castelfranchi, 2009; Vandekerckhove \& Panksepp, 2011). From this knowledge we advance the hypothesis that increased strength of the brainstem integrative signal excited for swimming generates a coherence of conscious experience by its regular repetition with the improved vigour of simultaneous, all-body sensory and motor signals.

The physical exertion of swimming certainly brings deep physiological benefits. The heart pumps faster, circulating more blood, oxygen, and energy not only to the muscles, but also to the brain, enhancing mental function. There is increased awareness of this link between exercise and thought, with particular attention in the literature to walking. It is a common understanding that walking or swimming or other forms of exercise enable thoughts and especially creative or 'divergent' thinking (Keinänen, 2016). Walking has long been associated with facilitating creativity in intellectual pursuits (ibid), from the Socratic peripatetic school (Peripatetic $=$ walking about) advanced by Aristotle and others (Athamatten, 2012), to Nietzsche who claimed in typical over-zealous fashion, "Only those thoughts that come by walking have any value" (Nietzsche, 2007, p. 9). Indeed, Henry David Thoreau commented, "Methinks that the moment my legs begin to move, my thoughts begin to flow." (Thoreau \& Blaisdell, 2011). Exercise of repetitive body movement can liberate thought.

In the case of Pum's lived experience, the act of mixed purposeful programs of action and their repetitions affords an intense feeling of integration in coherence of mind and body that is not otherwise felt, and that produces within it a sense of calm and affective equilibrium. ${ }^{2}$

Swimming and walking, and indeed any complex well-conceived pattern of behaviour, depends on regular cycles of action in an involuntary autonomic system, which assures the supply of oxygen and energy required for the rhythms of exercise. Done well, the body's physiological homeostasis can be maintained for many tens of minutes with the benefit of a constant, regular repetition of action and its felt sensory effects. Pum has developed her swimming practice of bi-weekly swims of fifty lengths, with regular periods of rest between

\footnotetext{
${ }^{2}$ Interestingly, this stands in contrast to the lateral thinking released for enhancement of the creative imagination in people without autism, and suggests that while some common mechanism is at work, its effects differ in their quality between autistic and non-autistic experience.
} 
sustained swimming to stretch the body. Stretches generate further skeletal muscular feedback and give her a growing sense of her body as hers in that moment. The movements and stretches performed together confirm ownership and self-control of her actions.

\section{Collage as Creative Therapy}

Pum is a practiced collage artist. Her practice developed from a need to explore, express and, inter-relate ideas and concepts from her own personal research and scholarly work. She has found collage-making exceptionally beneficial, cathartic and calming. Collage as a medium allows her mind to shift into a fluid multi-metaphorical state similar in dynamic complexity to her use of the water in swimming exercise, but with differences of composition and significance.

Like swimming, collage is a repetitive activity that allows discovery of new forms of experience and thought, and that flows with the activity to allow opportunity for the accessibility of affective and reflective self-awareness. It involves intention for regular cycles of repetitive sensorimotor activity - sorting of the paper, selection of images, cutting of fragments - all actions that demand integrated action across the body, stabilising posture and maintaining coherence of attention and coordinated action. Done easily with rehearsed skill, these simple activities can allow the mind to freely associate, playing off the images and their associations in the safety of a known environment that remains peacefully constant and unobtrusive.

Small, elementary micro-movements make large shifts of symbolic content with very little effort and only subtle movements of the muscles. A shift of the paper can juxtapose foreground and background in a new way to give rise to a significantly larger cognitive and perceptual shift in the created world. This aesthetic incidental control of the pictorial world can be very strengthening, reassuring, and rewarding. Again, a sense of agency is confirmed. Moreover, while each repetitive micro-movement is focussed on detail, controlled shifts of attention strive to piece together the detailed parts into a new whole. This strategy of creation exploits her autistic preference for applying detailed focal attention while at the same time allowing a return placement of the selected part into the whole again. Perspectival shifts from part to whole, back to part again, and so on to give the aesthetic feel of the growing picture, and this can enhance a sense of integration and coherence for the autistic artist in their practice. The aesthetic affective resonance of the work of art allows for and reinforces the maker's experience of affective, embodied self-awareness.

As with her swimming, Pum has found collage-making to be a calming activity that allows an integration of the whole self from across the vertical levels of mental processing, allowing thought of the experience to flow from its perceptual elements to recollections of their embodied resonances on combination.

The simple logical efforts, of sticking together a complex picture composition and swimming down a pool are constituted in the pursuit of repetitive sensorimotor action. In collage, this is the selection of print material, the cutting out, and the handling of discreet components. The amount of physical exertion for picture-making is significantly less than for any athletic task, and correspondingly the degree of perceptual and cognitive reflection can be considerably greater, feeding off the images and patterns that transform the elements of the collage in their creative exploration to make their meaning coherent. 
This requires a regular to-and-fro shift from internal-to-external percept, a movement from creative interior intuition to concrete external symbols. It enables a stitching together of conscious processing with thoughts and feelings that lie below conscious awareness. This process of composing an integrated picture can be cathartic, easing her internal tension which arises out of an autistic confusion of fragmented parts and contexts.

Collage affords Pum the discovery of a new synthesis of mind, allowing her autistic brain to get into the detail and to feel how each part shape the others, allowing comprehension and a new, literal appreciation of the attractiveness of the message as a coherent whole. By shifting focus across the details in collage-making, the whole visual composition is held and articulated, complete with thoughts and feelings communicated through the silent and still language of imagery. Pum feels this benefit, a satisfaction in the work of interpretation.

Collage is hugely strengthening for Pum, because she has to capture its sense not in words, but in images of tangible static imagery made in scraps of concrete detail. It lets her autistic mind to do what it likes to do, focus on the detail, and lets the autistic brain do what it likes to do, get stuck in and focussed in on the activity or project. Then, when one is locked into that activity of repetitive sensorimotor process, the creative process kicks in. Something new happens: a new, integrative state of consciousness. And that new something enables growth of her creative self, enables Self-relating, and an integration of her sensory-affective experience made coherent and meaningful in her exploratory, expressive body movement. It opens new, higher states of reflective self-consciousness. This is incalculably beneficial, its insights translated for healthier everyday living.

The other important feature of collage is that it captures one's interest in the little fiddly movements some individuals with ASD are compelled to repeat, normally with little product or enjoyment to be shared. However, by embedding this repetitive behaviour in a structured routine, a creative opportunity is encouraged. Thus, if a supportive and sensitive practitioner can foster one's engagement with concrete materials, one can help the individual with autism access an evolving creative dimension. When acting in an asocial setting, and left alone, the individual collage-maker necessarily communicates with him- or herself, through the aesthetic, signs and symbols of their work. Thus, when Pum is making a collage, she is engaged in Self-related processing. She is 'dialoguing' with different aspects of her Self free from social responsibility or performative requirements. She is solely engaged in communicating to and with her Self. She likens this process to a private form of waking dream, in which she can slowly discover herself.

In Pum's experience, good collage comes from three to four hours of continuous practice. It is in such sustained activity that she begins to synthesise thoughts, feelings, and ideas working below the level of conscious reflection to solve problems, and that is when she begins to feel an intuitive, integrated and coherent sense of self. It gives her new, inner strength that enables her to survive and cope with the relentless performative demands of her autism disorder and the everyday, practical activities that support her physical, mental and emotional wellbeing. This deeply restorative creative behaviour has allowed her to understand her need to withdraw from the conventional social world, whilst supporting her growth within her private creative work and research.

Collage is embodied self-reflexivity in changing sensorimotor movements. Movements of the pieces of collage generate feed-back that is satisfying, or not. And through appraisals and self-reflection, something new and rewarding can be established. As the repetition of these 
movements proceed, Pum discovers a transition in her consciousness from its usual state of tense, fragmented, unfocussed attention, to one of more relaxed coherence of perception, action, and reflection. This transitioned state allows an appreciation of experiences immediately at hand to include both internal and external awareness. New to this experience is a feeling of integrated coherence, with mind and body working synchronously together in balanced harmony, not felt passively during the flux of daily experience or under the demands of rules and routines in a spontaneously changing external or internal environment. Autism presents disorder in the normal experience of self-conscious purposeful and valued habits of a life alone and in relationships. It can be helped by giving it clarity and strength by changing personal and social demands for action, and social interaction.

\section{Sensitive Care for the Primary Self of a Companion with Autism: Supportive Structures for Routines of Practice}

From consideration of the principles of brain control of purposeful muscular activity of the human body in awareness of its environments, objective and social, with appreciation of the efforts and emotions involved, we have outlined a theory of autism, its development and how its problems may be alleviated by relational and sympathetic therapy that adapts the urge for repetitive behaviour into constructive routines (Trevarthen \& Delafield-Butt, 2013b). The foundation of our approach is in the phylogenetic record of vertebrate brain systems that direct and evaluate movements with many senses for feedback of biomechanical effects between the body and the environment, as well as within the body between its inner vital organs, media for sustaining nutritive well-being, and harmonisation of activity in its skeletomuscular system to maintain health and growth of the integrated whole Self (Bosco et al., 2018; Dadalko \& Travers, 2018; J. Delafield-Butt \& Trevarthen, 2017).

A focus for therapeutic intervention can be to improve intra-personal coherence and selfawareness of the different levels of processing, especially the difference between the rational, reflective analytic consciousness (Figure 1; tertiary kind) and a more ontogenetically primitive and core affective and embodied self (Figure 1; primary kind) that is able to integrate the rational thoughts from 'above' with the feelings and desires of the present moment, made real in active bodily expression. Strengthening this self-regulation can lead to gains in cooperative awareness if the emotional processes of inner, intra-personal sympathetic relating are enriched (Delafield-Butt et al., 2019; Delafield-Butt et al., 2020).

It is for this reason that we caution against behavioural therapies such as those based on Adaptive Behavioural Analysis that focus on the performative aspects of communication and action, but that do not work to help the individual to find the particular form of expression that carries their inner feeling. Performative methods train the intellect to control and rule the body in service of socially acceptable norms of shape or form. And while this may yield some benefit for the family and community by creating an apparently adapted individual with socially normalised behaviours, that individual may very likely remain internally stressed deeper in the body, because performative communication can remain disconnected from personal motives, and remain meaningless or empty.

In such a case, the autistic individual can be left stranded, disconnected, and unable to relate to oneself let alone to another. This aloneness can be disorientating and the meaninglessness 
stressful. It can be explained as a dissonance between the primary self and the social expectations learned by the secondary and tertiary levels of processing, incurring an internal, chronic distress and further cutting off and entrenching dissociation with primary affective experience.

The organisation of autism and its phenomena described in this paper give information for individuals with autism, and for parents and professionals who offer care and support for them. We offer simple, practical advice on securing coherent, productive and pleasurable Self-awareness with motive impulses to enrich experience and give value to habits and knowledge. This is not about appropriate behaviour or reciprocal communication of facts in shared meaning for social use of conventional tools or media, which is an enterprise that can arouse self-judging anxiety or shame. It is about finding internal coherence in one's sense of self, and making the best of one's autistic impulses and particular needs.

\section{Establishing a routine for safe practice}

Pum's account of her active use of swimming and collage for building strength in her ability to self-relate confirms that such creative activity can be helpful not only as therapeutic for autistic anxiety, but for opening new possibilities for thoughtful reflection, personal development, and creative expression that can allow for an integration of the Self, and only later for one's personal experience to be communicated, and shared in safe and sustaining relations. Both activities were conducted alone, in quiet isolation, exploiting familiar environments and set within routines of daily and weekly patterns. A supportive context can be generated by caring others with practical prompts, such as "in 10 minutes we will be stopping", or by showing an object that signals "coming to the end" of an activity. These simple steps encourage security in knowing what is to come. By learning what a movement of the body is and how its activity draws to completion clarifies how the feeling is embodied, and lived.

Change and transitions between states of being can cause the individual with autism significant discomfort. Performing simple rituals of preparation and travel to the swimming pool, or setting out the items to start a college, can itself be anxiety-provoking. Without support, the individual may find this anxiety too difficult to overcome alone. By understanding the individual's autism's needs for clear, transparent expectations with explicit prompts, a caring supporter can facilitate management of the individual's growing anxieties about the change-to-come. This can be done simply through rehearsal and help with planning the details and preparing for the routine.

Each step is important: preparing the swimming costume and towel, packing the bag, wearing the right clothes for the outside, leaving the house, and travelling to the pool. Familiarity with this routine is paramount to reducing anxiety, and maintaining consistency in the patterns is extremely helpful. Keeping to a regular time of day and day of the week is very helpful. Once at the pool, regular use of the same changing room, shower, and swimming lane all help to present a degree of constant, regular familiarity in the routine. This will lead to a building up of an affirmative experience where anxiety levels become reduced over the weeks, months, and years. This will promote a growing sense of self-control, self-confidence, and selfempowerment. 
It is worth noting that no matter how simple or complex the task to hand, the carer who is observant and responsive to expectations and past experiences, and respectful of reassuring routines, will assist the individual to become more confident and secure. It may be important to help an individual with autism to identify their needs so they may learn how to communicate them, and find how to manage them for themselves, and become better resourced in self-regulation of vitality. The autistic child needs this support to feel the story of each simple routine, so they can practice it again by themselves. From Pum's experience, the ideal help for the child with autism to surpass developmental hurdles is at their own pace, encouraging known routines and actions that already work, however simple they may be.

\section{Supporting an Integration of the Self, for Self-Awareness and Self-Empowerment}

The experience of feelings and motives for action and interaction of the Core Self can be very different from that of the higher-order, Conceptually-Oriented Self. This higher-order Self is developed socially with others, and is therefore structured and organised by conventional social expectations, including instructions. It is shaped by outside social environments. Altogether these external influences on the priorities and values of the Tertiary Self may dissociate it from the feelings, desires, and wishes of the Core Self, which may become trapped and unexpressed.

This can lead to "difficult", "disruptive", or "challenging" behaviours. But it can be damaging for an individual to be defined as such, and it neglects the role and responsibility of social expectation and caregiver support when these behaviours result from a mismatch between these social expectations and tolerances, and lack of 'connection' an individual's needs and modes of feeling, thinking, and being. This is why we advise support for them to become more happily self-aware, ready and able to ask for help and therefore to manage their autism better, in friendship.

The Core Self is non-verbal, expressive in the language of body movement, gesture, and intonation of the voice. It may be that to emphasise verbal language acquisition in some children - 'to get them to talk' - may miss the fact that they don't speak because they are not ready for that level of abstract, verbal narrative and sense-making, and must rely on intuitive non-verbal elements of self-expression. As in typical development, there needs to develop first a "languaging" of the self in actions of the body (Halliday, 1975). In the sensory-motor realm of psychological functioning, the motor life embeds and supports the awareness of the senses, physically yolking them to the sensory, giving structure to and learning of selfconsciousness from sensory perceptions.

\section{All Behaviour is Communication}

Parents as custodians of mental and emotional life can often be overly concerned with what their child 'can't do', overlooking what their child 'can do'. We say it is fundamentally important for the child and adult with autism to find their own language on their own bodily level, in extraverted and introverted activity. Throwing a ball and catching, jumping on a trampoline, or moving to music gives that child an experience of their body. And at the same time it's activity in action is creating life experiences at a cognitive and sensory level, creating new neural pathways. Just by doing something in a structure or project, with or without a 
caregiver. Thus, the best caregiver support is attentive and observant to the opening, to where the child is going to be able to channel communication with their self and body.

Key Conclusions, How Individual Vitality, With Emotional Appreciation of Experience from Acting, Grows in Brain and Body of a Person With ASD, and How It May Benefit from Special Care

This paper has examined the evidence for a nested hierarchy of human conscious experience that exists at all stages of development of body and brain, and the special nature of autism disorder which disrupts the efficient integration in neural centres of the primary Core Self, and the development of coherence in communication of neural and motor effects reaching between levels to enrich the consciousness of the top level. We identified the need in each person, child or adult, for intra-personal communication to be supported and strengthened as the Self-in-Relations of an intimate and structured social life. This is fundamental learning for self-care and self-development.

By analysis of Pum's personal experience and collaboration with her perspective and insights of her experience of autism, we consider the benefits from two energetic and demanding sensorimotor activities, swimming and collage, which she knows to be beneficial for the integrative access between higher and core levels of her Self, and that she believes can be made beneficial for individuals with autism.

We confirm that genuine inter-personal communication in parental care or professional therapy can bring benefit only once the autistic individual is in touch with his or her Core Self, and can source meaningful engagement with others from this place of assertion to move with emotional appraisal. We identify means that caring persons can deploy to help the person with autism become more complete, embodied and coherent, and to help them express their individuality ready to share an integral meaning in life's movements and what they discover.

\section{Acknowledgement}

We kindly thank Ruth Mutch for her assistance with Figure 2. 


\section{References}

Athamatten, E. (2012). Philosophy begins with wander. Nomadic Sojourns Journal, 2, 13-21.

Bernstein, N. A. (1967). The Co-ordination and Regulation of Movements. Oxford: Pergamon Press.

Bosco, P., Giuliano, A., Delafield-Butt, J., Muratori, F., Calderoni, S., \& Retico, A. (2018). Brainstem enlargement in preschool children with autism: Results from an intermethod agreement study of segmentation algorithms. Human Brain Mapping.

Bruner, J. S. (2003). Making Stories: Law, Literature, and Life. New York: Farrar, Strauss, \& Giroux.

Buzsáki, G. (2006). Rhythms of the Brain. Oxford: Oxford University Press.

Chomsky, N. (1957). Syntactic Structures. The Hague/Paris: Mouton.

Coghill, G. E. (1929). Anatomy and the Problem of Behaviour. Cambridge: Cambridge University Press.

Dadalko, O. I., \& Travers, B. G. (2018). Evidence for Brainstem Contributions to Autism Spectrum Disorders. Frontiers in Integrative Neuroscience, 12(47).

Daniel, S. (2019). Loops and Jazz Gaps: Engaging the Feedforward Qualities of Communicative Musicality in Play Therapy with Children with Autism. The Arts in Psychotherapy, 65, 101595.

Davis, K. L., \& Panksepp, J. (2011). The brain's emotional foundations of human personality and the Affective Neuroscience Personality Scales. Neuroscience \& Biobehavioral Reviews, 35(9), 1946-1958.

Delafield-Butt, J., \& Trevarthen, C. (2017). On the Brainstem Origin of Autism: Disruption to Movements of the Primary Self. In E. Torres \& C. Whyatt (Eds.), Autism: The Movement Sensing Perspective): Taylor \& Francis CRC Press.

Delafield-Butt, J., Trevarthen, C., Rowe, P., \& Gillberg, C. (2019). Being misunderstood in autism: The role of motor disruption in expressive communication, implications for satisfying social relations. Behavioral and Brain Sciences, 42, e86.

Delafield-Butt, J. T., \& Gangopadhyay, N. (2013). Sensorimotor intentionality: The origins of intentionality in prospective agent action. Developmental Review, 33(4), 399-425.

Delafield-Butt, J. T., \& Trevarthen, C. (2013). Theories of the development of human communication. In P. Cobley \& P. Schultz (Eds.), Theories and Models of Communication (pp. 199-222). Berlin/Boston: De Gruyter Mouton.

Delafield-Butt, J. T., \& Trevarthen, C. (2015). The Ontogenesis of Narrative: From moving to meaning. Frontiers in Psychology, 6, 01157.

Delafield-Butt, J. T., Zeedyk, M. S., Harder, S., Vaever, M. S., \& Caldwell, P. (2020). Making Meaning Together: Embodied Narratives in a Case of Severe Autism. Psychopathology, 53(2), 60-73.

Douglas, H. (2007). Containment and Reciprocity: Integrating Psychoanalytic Theory and Child Development Research for Work with Children. London \& New York: Routledge. 
Ford, C. (2013). Dancing with horses: Combining dance/movement therapy and equine facilitated psychotherapy. American Journal of Dance Therapy, 35(2), 93-117.

Gallagher, S. (2014). The cruel and unusual phenomenology of solitary confinement. Frontiers in Psychology, 5(585).

Gibson, J. J. (1977). The Theory of Affordances. In R. Shaw \& J. Bransford (Eds.), Perceiving, Acting, and Knowing). Hillsdale, NJ: Erlbaum.

Gigliotta, O., Pezzulo, G., \& Nolfi, S. (2011). Evolution of a predictive internal model in an embodied and situated agent. Theory in Biosciences.

Gillberg, C. L. (1992). The Emanuel Miller Memorial Lecture 1991. Autism and autistic-like conditions: subclasses among disorders of empathy. J Child Psychol Psychiatry, 33(5), 813842.

Halliday, M. A. K. (1975). Learning How to Mean: Explorations in the development of language. London: Edward Arnold.

Halliday, M. A. K. (1978). Language as Social Semiotic: The social interpretation of language and meaning. London: Edward Arnold.

Hallmayer, J., Cleveland, S., Torres, A., \& et al. (2011). Genetic heritability and shared environmental factors among twin pairs with autism. Archives of General Psychiatry, 68(11), 1095-1102.

Happé, F. (1999). Autism: cognitive deficit or cognitive style? Trends Cogn Sci, 3(6), 216-222. Happé, F. (2003). Theory of mind and the self. Ann N Y Acad Sci, 1001, 134-144.

Happé, F., \& Frith, U. (2006). The Weak Coherence Account: Detail-focused Cognitive Style in Autism Spectrum Disorders. Journal of Autism and Developmental Disorders, 36(1), 5-25.

Happé, F. G. E. (1997). Central coherence and theory of mind in autism: Reading homographs in context. British Journal of Developmental Psychology, 15(1), 1-12.

Happé, F. G. E., \& Booth, R. D. L. (2008). The Power of the Positive: Revisiting Weak Coherence in Autism Spectrum Disorders. Quarterly Journal of Experimental Psychology, 61(1), 50-63.

Hobson, P., \& Hobson, J. (2011). Joint attention or joint engagement? Insights from autism. In Joint attention: New developments in psychology, philosophy of mind, and social neuroscience. (pp. 115-135). Cambridge, MA, US: MIT Press.

Hobson, R. P. (1993). Autism and the development of mind. Hillsdale, NJ: Lawrence Erlbaum Associates.

Iverson, J. M. (2010). Developing language in a developing body: the relationship between motor development and language development. Journal of Child Language, 37, 229-261.

James, W. (1890). The principles of psychology. New York: Dover.

Jaswal, V. K., \& Akhtar, N. (2018). Being vs. Appearing Socially Uninterested: Challenging Assumptions about Social Motivation in Autism. Behavioral and Brain Sciences, 1-84.

Keinänen, M. (2016). Taking your mind for a walk: a qualitative investigation of walking and thinking among nine Norwegian academics. Higher Education, 71(4), 593-605.

Koch, S. (2016). Body image in autism: An exploratory study on the effect of dance movement therapy. Autism Open Access, 6. 
Koch, S. C., Mehl, L., Sobanski, E., Sieber, M., \& Fuchs, T. (2015). Fixing the mirrors: a feasibility study of the effects of dance movement therapy on young adults with autism spectrum disorder. Autism, 19(3), 338-350.

Lakoff, G., \& Johnson, M. (1980). Metaphores We Live By. Chicago: Chicago University Press. Lakoff, G., \& johnson, M. (1999). Philosophy in the Flesh: The embodied mind and its challenge to western thought: Basic Books.

Langer, S. K. (1942). Philosophy in a New Key: A Study in the Symbolism of Reason, Rite, and Art. Cambridge MA: Harvard University Press.

Lashley, K. S. (1951). The problem of serial order in behavior. In: L. A. Jeffress (Ed.),. Cerebral mechanisms in behavior, pp. 112-136. New York: Wiley.

MacLean, P. D. (1990). The Triune Brain in Evolution: Role in paleocerebral functions. New York: Plenum Press.

Macmurray, J. (1957). The Self as Agent. London: Faber and Faber.

Macmurray, J. (1961) Persons in Relation (Volume II of The Form of the Personal) London: Faber and Faber.

Malloch, S. (1999) Mother and infants and communicative musicality. In: Rhythms, Musical Narrative, and the Origins of Human Communication. Musicae Scientiae, Special Issue, 19992000, Deliège, I., ed. Liège, Belgium: European Society for the Cognitive Sciences of Music, pp. 29-57.

Malloch, S., \& Trevarthen, C. (2009a). Musicality: Communicating the vitality and interests of life. In S. Malloch \& C. Trevarthen (Eds.), Communicative Musicality: Exploring the basis of human companionship (pp. 1-12). Oxford: Oxford University Press.

Malloch, S., \& Trevarthen, C. (Eds.). (2009b). Communicative Musicality: Exploring the basis of human companionship. Oxford: Oxford University Press.

May, T., Chan, E. S., Lindor, E., McGinley, J., Skouteris, H., Austin, D., et al. (2019). Physical, cognitive, psychological and social effects of dance in children with disabilities: systematic review and meta-analysis. Disabil Rehabil, 1-14.

Merker, B. (2005). The liabilities of mobility: A selection pressure for the transition to consciousness in animal evolution. Consciousness and Cognition, 14, 89-114.

Merker, B. (2007). Consciousness without a cerebral cortex: A challenge for neuroscience and medicine. Behavioral and Brain Sciences, 30, 63-134.

Merker, B. (2013). The efference cascade, consciousness, and its self: naturalizing the first person pivot of action control. Front Psychol, 4, 501.

Nietzsche, F. W. (2007). Twilight of the Idols with the Antichrist and Ecce Homo: Wordsworth Editions.

Northoff, G., \& Panksepp, J. (2008). The trans-species concept of self and the subcorticalcortical midline system. Trends in Cognitive Sciences, 12, 259-264.

Panksepp, J. (1991). Affective Neuroscience: A conceptual framework for the neurobiological study of emotions. In K. T. Strongman (Ed.), International Review of Studies on Emotion). New York: Wiley \& Sons. 
Panksepp, J. (1992). A critical role for "affective neuroscience" in resolving what is basic about basic emotions. Psychol Rev, 99(3), 554-560.

Panksepp, J. (1998a). Affective Neuroscience: The foundations of human and animal emotions. New York: Oxford University Press.

Panksepp, J. (1998b). The periconscious substrates of consciousness: Affective states and the evolutionary origins of the SELF. Journal of Consciousness Studies, 5(5-6), 5-6.

Panksepp, J., \& Biven, L. (2012). The Archaeology of Mind: Neuroevolutionary Origins of Human Emotions. New York: Norton.

Penfield, W., \& Jasper, H. H. (1954). Epilepsy and the functional anatomy of the human brain. London: Little, Brown, and Co.

Pezzulo, G., \& Castelfranchi, C. (2009). Thinking as the control of imagination: a conceptual framework for goal-directed systems. Psychological Research, 73, 559-577.

Pinker, S. (1994). The Language Instict. Londong and New York: Penguin Books.

Porges, S. W. (2001). The polyvagal theory: phylogenetic substrates of a social nervous system. Int J Psychophysiol, 42(2), 123-146.

Posner, D. S. (2016). Review of W. Solomon, C. Holland, M. J. Middleton: Autism and Understanding: The Waldon Approach to Child Development. Journal of Autism and Developmental Disorders, 46, 1498-1499.

Rajendran, G., \& Mitchell, P. (2007). Cognitive theories of autism. Developmental Review, $27(2), 224-260$.

Reed, E. (1996). Encountering the World: Towards an Ecological Psychology. New York: Oxford University Press.

Reid, T. (1764). An Inquiry into the Human Mind on the Principles of Common Sense. Edinburgh: A. Kinkaid \& J. Bell.

Rinehart, N. J., Jeste, S., \& Wilson, R. B. (2018). Organized physical activity programs: improving motor and non-motor symptoms in neurodevelopmental disorders. Dev Med Child Neurol, 60(9), 856-857.

Robledo, J., Donnellan, A. M., \& Strandt-Conroy, K. (2012). An exploration of sensory and movement differences from the perspective of individuals with autism. Frontiers in integrative neuroscience, 6, 107-107.

Richer, J. (2001). The Insufficient Integration of Self and Other in Autism. In J. Richer \& S. Coates (Eds.), The Search for Coherence (pp. 36-52). London: Jessica Kingsley Publishers.

Sandin, S., Lichtenstein, P., Kuja-Halkola, R., Larsson, H., Hultman, C. M., \& Reichenberg, A. (2014). The familial risk of autism. JAMA, 311(17), 1770-1777.

Sherrington, C. (1906). The integrative action of the nervous system. New Haven, CT: Yale University Press.

Shewmon, D. A., Holmse, D. A., \& Byrne, P. A. (1999). Consciousness in congenitally decorticate children: Developmental vegetative state as self-fulfilling prophecy. Developmental Medicine and Child Neurology, 41, 364-374. 
Solms, M., \& Panksepp, J. (2012). The "Id" Knows More than the "Ego" Admits: Neuropsychoanalytic and Primal Consciousness Perspectives on the Interface Between Affective and Cognitive Neuroscience. Brain Science, 2, 147-174.

St Claire, C., Danon-Boileau, L., \& Trevarthen, C. (2007). Signs of autism in infancy: Sensitivity for rhythms of expression in communication. In S. Acquarone (Ed.), Signs of Autism in Infants: Recognition and Early Intervention (pp. 21-45). London: Karnac Books.

Stern, D. N. (2000). The Interpersonal World of the Infant: A View from Psychoanalysis and Development Psychology (Second ed.). New York: Basic Books.

Stern, D. N. (2010). Forms of Vitality. Oxford: Oxford University Press.

Thoreau, H. D., \& Blaisdell, B. (2011). Thoreau: A book of quotations. New York: Dover Publications Inc.

Trevarthen, C. (2003). Memory as motor activity: The brain making time, going places and finding objectives in company. In German as: Frühe Kommunikation und autobiographisches Gedächtnis. BIOS: Zeitschrift für Biographieforschung, Oral History und Lebensverlaufsanalysen, 2/2002, 213-240.

Trevarthen, C. (2005). Stepping away from the mirror: Pride and shame in adventures of companionship. Reflections on the nature and emotional needs of infant intersubjectivity. In, C.S. Carter, L. Ahnert, K. E. Grossman, S. B. Hrdy, M. E. Lamb, S. W. Porges, and N. Sachser, eds. Attachment and Bonding: A New Synthesis. Dahlem Workshop Report, 92. Cambridge, MA: The MIT Press. pp. 55-84.

Trevarthen, C. (2011). Born for art, and the joyful companionship of fiction. In D. Narvaez, J. Panksepp, A. Schore \& T. Gleason (Eds.), Human Nature, Early Experience and the Environment of Evolutionary Adaptedness). New York: Oxford University Press.

Trevarthen, C. (2014). Educational Psychology in Scotland. Special Issue: Video Interaction Guidance, 15(null), 10.

Trevarthen, C. (2015). Stories of truth and beauty in the sound of moving. In P. A. Brandt (Ed.), Sigata: Annals of Semiotics): University of Liège.

Trevarthen, C., Aitken, K. J., Nagy, E., Delafield-Butt, J. T., \& Vandekerckhove, M. (2006). Collaborative Regulations of Vitality in Early Childhood: Stress in Intimate Relationships and Postnatal Psychopathology. In D. Cicchetti \& D. J. Cohen (Eds.), Developmental Psychopathology (pp. 65-126). New York: John Wiley \& Sons.

Trevarthen, C., Daniel, S., \& Trevarthen, C. (2017). Rhythms of relating in children's therapies (Vol. null).

Trevarthen, C., \& Delafield-Butt, J. T. (2013a). Autism as a developmental disorder in intentional movement and affective engagement. Frontiers in Integrative Neuroscience, 7, 49.

Trevarthen, C., \& Delafield-Butt, J. T. (2013b). Biology of Shared Meaning and Language Development: Regulating the Life of Narratives. In M. Legerstee, D. Haley \& M. Bornstein (Eds.), The Infant Mind: Origins of the Social Brain (pp. 167-199). New York: Guildford Press.

Trevarthen, C., \& Delafield-Butt, J. T. (2015). The Infant's Creative Vitality, In Projects of SelfDiscovery and Shared Meaning: How They Anticipate School, and Make It Fruitful. In S. Robson \& S. F. Quinn (Eds.), International Handbook of Young Children's Thinking and Understanding (pp. 3-18). Abingdon, Oxfordshire \& New York: Routledge. 
Trevarthen, C., \& Delafield-Butt, J. T. (2017). Development of Consciousness. In B. Hopkins, E. Geangu \& S. Linkenauger (Eds.), Cambridge Encyclopedia of Child Development (pp. 821-835). Cambridge: Cambridge University Press.

Trevarthen, C., \& Daniel, S. (2005). Disorganized rhythm and synchrony: Early signs of autism and Rett syndrome. Brain and Development, 27, S25-S34.

Trevarthen, C., Gratier, M., \& Osborne, N. (2014). The human nature of culture and education. Wiley Interdisciplinary Reviews: Cognitive Science, 5(2), 173-192.

Turner, F. (1991). Beauty: The Value of Values. Charlottesville: University Press of Virginia.

Vandekerckhove, M., \& Panksepp, J. (2009). The flow of anoetic to noetic and autonoetic consciousness: A vision of unknowing (anoetic) and knowing (noetic) consciousness in the remembrance of things past and imagined futures. Consciousness and Cognition, 18, 10181028.

Vandekerckhove, M., \& Panksepp, J. (2011). A neurocognitive theory of higher mental emergence: From anoetic affective experiences to noetic knowledge and autonoetic awareness. Neuroscience \& Biobehavioral Reviews, 35 (9), 2017-2025.

Williams, D. (1996). Autism: An Inside-Out Approach: An Innovative Look at the 'Mechanics' of 'Autism' and its Developmental 'Cousins'. London: Jessica Kingsley.

Winnicott, D. (2001/1971). Playing and Reality. London: Routledge.

Winnicott, D. W. (1954). Mind and Its Relation to the Psyche-Soma. British Journal of Medical Psychology, 27(4), 201-209.

Winnicott, D. W. (1960). Ego Distortion in Terms of True and False Self. In D. W. Winnicott (Ed.), The Maturational Processes and the Facilitating Environment: Studies in the Theory of Emotional Development (pp. 140-152). London: Karnac Books.

Zeki, S. (1993). A Vision of the Brain. Oxford: Blackwell.

Zeki, S. (1999). Inner Vision. Oxford: Oxford University Press.

\section{Appendix}

Profile of a collaged mind finding sense and synthesis in the language of movement, fragment and aesthetic coherence. A collage by Pum.

This collage is a composition of parts that speaks of the relationship between autism, sensorymotor processes, spatiotemporal delays, problems with control, tolerance and connection in the infrastructures of the primary, secondary and tertiary processes of brain communication. This thesis presents a new perspective of autism deploying the concept of a fundamental disruption to the ability to inter-relate the different brain regions leaving the core Self sealed off, disconnected, disembodied, and importantly unavailable to self-regulate in accordance with the organisms ever-changing biopsychosocial environmental needs. 
The elements of the collage are presented roughly spatially in corresponding regions of the brain, i.e. limbic system and amygdala, cerebellum, vestibular apparatus of the inner ear, thalamus, and neocortex.

1. Giant ear. This giant ear represents the sensory apparatus of hearing and the vestibular sense of balance. Pum's sensory sensitivity profile includes hyper-sensitivity to sound; she can hear her contact lens drop on a carpeted floor. The inner ear is the site of the vestibular sense and it plays an important part in attention regulation, the ability to focus and concentrate. Pum experiences a delayed audio and visual processing disparity that creates out-of-synch information inputs. Pum is also hypersensitive to smell, the ear is positioned over eye and olfactory bulb

2. Split torso diagram. This is spatially placed in midbrain area of limbic system housing the amygdala, hypothalamus and thalamus. Sensory-motor, sensory-affective and cognitive perceptions collide and fragment processing. Output and input exchange and interrelate internal subjective experience to the to external world of objects, others and stimulus. The conflict and tension created by the autistic brain's difficulties between managing the incoming and outgoing communications overwhelm and disrupt the body-mind relationship.

3. Concrete dam barrier built. The architecture of compliance and withdrawal - it is a protective, mal-adaptative defense to protect the ungerminated Core Self (Winnicott, 1960).

4. The wheel. The wheel represents motion, movement embedded in the revolution of repetition - the cycle of movement from the micro-cellular level to the macro-skeletal muscular level (J. T. Delafield-Butt \& Gangopadhyay, 2013; Trevarthen \& Delafield-Butt, 2013).

5. Staircase. The staircase is like the spinal column. It leads down to a landing in the body, the home of the human being's embodied self, a space where psyche and soma work together to generate mindfulness (Winnicott, 1954).

6. Metronome needle. The metronomic is a time-keeping device symbolising temporal displacement of experience between inner processing and the outer world environment (J. Delafield-Butt \& Trevarthen, 2017).

7. Face facing backwards, looking inwards. This area of the collage is synthesised into a depiction of memory, innovation and creativity that is generated through processes orchestrated by the cerebellum region of the brain. Pum has an extraordinary strange and vivid long-term memory. The occipital lobe area at the back of the head is where insight is generated through the coupling-up and categorising of visual perceptual details into grouped concepts (Zeki, 1993, 1999).

8. Child with book, looking and learning. This learning, conditioning, behavioural part of the brain responds to the emotional valance of experiences. Unpleasant experiences become charged with negative associations, while for Pum learning, knowledge acquisition, school work was charged with positive experiences of self-control and acceptance and a high regard from Other. Thus, social scripts and social coding was copied and tattooed (the computer 
chip being indented with programming circuitry) into the neocortex, the tertiary level brain processing.

9. Scaffolding precariously placed in a ridged, fixed disorganised space. As indicated by the cloud of strange detailed marks, which appears to the right of the scaffolding poles, this is the region of the forebrain responsible for executive function (the ability to think into the future) planning organisation. Individuals with autism have problems with executive functioning (Rajendran \& Mitchell, 2007).

10. Expiration the cloud of breath, or speech bubble of chromosomes, the complex strands which hold and fold their genetic mysteries. Pum believes that the branch of science epigenetics is showing up just how important lifestyle choices (how the interactions with our environment shape our being, and the expressions of our genes) are. Autism aetiology is complex, involving both genetic and environmental factors (Hallmayer, Cleveland, Torres, \& et al., 2011)(Sandin et al., 2014).

By adopting certain activities (movement based and creative-led activities), we would argue that we can perhaps turn down the influence of any autism genetic material, we can enhance the brain's potential by supporting the autism needs, therefore encouraging the development of a more integrated brain, body and environment, one where the autism syndrome is managed through diet, low arousal lifestyle and emphasis of Primary Self communication, in order to foster an individual's ability to better self-regulate and to better tolerate the inevitable changes that come with being human. 